Article

\title{
Influence of Waterproof Films on the Atomization Behavior of Surface Acoustic Waves
}

\author{
Qing-Yun Huang, Hong Hu *, Jun-Long Han, Yu-Lin Lei and Xiao-Qing Yang \\ School of Mechanical Engineering and Automation, Harbin Institute of Technology, Shenzhen, \\ Guangdong 518055, China; huanglaoxie123456@163.com (Q.-Y.H.); hanjunlongxf@163.com (J.-L.H.); \\ happy_flying@126.com (Y.-L.L.); 13713955190@163.com (X.-Q.Y.) \\ * Correspondence: honghu@hit.edu.cn
}

Received: 25 October 2019; Accepted: 18 November 2019; Published: 19 November 2019

\begin{abstract}
One of the reasons why commercial application of surface acoustic wave (SAW) atomization is not possible is due to the condensation of aerosol droplets generated during atomization, which drip on the interdigitated transducer (IDT), thereby causing electrodes to short-circuit. In order to solve this problem, a SU-8-2002 film coating on an IDT is proposed in this paper. The waterproof performance of the film coating was tested on a surface acoustic wave (SAW) device several times. The experimental results reveal that the film coating was robust. The experiment also investigated the effects of the SU-8-2002 film on atomization behavior and heating.
\end{abstract}

Keywords: surface acoustic wave (SAW); film coating; atomization behavior

\section{Introduction}

The generation of micron- and submicron-sized sprays is important for many industrial processes. Dense, monodisperse aerosols with a controllable size are widely employed in many applications, such as fuel injection, agriculture sprays, mass spectrometry, ink-jet printing, and pulmonary drug delivery. The essence of atomization is that external forces overcome the capillary force within the fluid and decompose into aerosol droplets. Common atomization methods include pressurized nozzles, electrospraying, ink-jets, and ultrasonic atomization. Among these methods, ultrasonic atomization has been widely investigated and utilized.

Since the first description of ultrasonic atomization by Wood and Loomis et al. [1], a series of studies have focused on ultrasonic atomization mechanisms and characteristics. Lang et al. [2] used alternating signals to drive piezoelectric transducers, thereby generating ultrasonic and measured the droplet sizes from the breakup of the capillary wave on the liquid surface; they concluded that the droplet size was directly proportional to the wavelength of the capillary waves. Lang et al. also proposed a formula describing the relationship between the droplet size and excitation frequency, which showed a tendency for the droplet size to decrease with increasing excitation frequency [2]. However, due to material limitations, excitation frequency was limited to $3 \mathrm{MHz}$. In biological applications, this low frequency would damage molecules. Although the ultrasonic atomizer is small compared to other atomizers, it is difficult to miniaturize to the point where it can be hand-held.

Kurosawa et al. [3,4] proposed a new type of ultrasonic atomizer using a surface acoustic wave (SAW) device. A SAW is a nanometer-order amplitude acoustic wave. SAW technology has been widely used in filters, biosensors, wireless transmission, and radio frequency (RF) duplexers and has potential applications in the field of microfluidics. Its role is to propagate along the surface of a substrate and decay within one or two wavelengths into the substrate depth, with little loss in the direction of the surface propagation. The most common SAW use in microfluidics is the Rayleigh wave, which attenuates a leaky surface acoustic wave (LSAW) when it comes into contact with droplets, 
due to a mismatch of sound velocity in the fluid (about $1485 \mathrm{~m} / \mathrm{s}$ for water) and piezoelectric substrate (3965 m/s for $128^{\circ} \mathrm{Y}-\mathrm{X}$ lithium niobate). The LSAW attenuates along the propagation path, and that diffracts a longitudinal wave enters the droplet at the Rayleigh angle, $\theta_{R}$. It attenuates in a viscous fluid medium, then the longitudinal wave propagates within the droplet, generating a pressure gradient that causes acoustic flow within the droplet. As the power increases, the droplet shows a series of dynamics, such as vibration, pumping, jetting, and atomization. When the input power reaches a threshold value, a capillary wave is generated on the surface of the droplet and starts to break up, subsequently forming atomization. In order to achieve high performance using SAW devices, the choices of Piezo substrate materials are significant. The most common materials are lithium tantalate $\left(\mathrm{LiTaO}_{3}\right)$, lithium niobate $\left(\mathrm{LiNbO}_{3}\right)$, zinc oxide $(\mathrm{ZnO})$, and aluminum nitride $(\mathrm{AlN})$. $\mathrm{LiNbO}_{3}$ crystals characteristically have a large electromechanical coupling coefficient and a small propagation loss, so they are suitable for fabricating low-loss SAW devices with broadband. So far, this material has been widely used in SAW devices. $\mathrm{LiTaO}_{3}$ crystals have a large electromechanical coupling coefficient similar to $\mathrm{LiNbO}_{3}$, but the temperature stability of $\mathrm{LiTaO}_{3}$ crystals is better than lithium niobate crystals. However, $\mathrm{LiTaO}_{3}$ crystals have a high melting point, complex production equipment and technology, and high production costs. Since the 1960s, the development of piezoelectric and ferroelectric thin films has made it possible for piezoelectric thin films to be used in SAW devices. At present, more research is being carried out regarding zinc oxide and aluminum nitride deposition onto diamond films. Among them, the ZnO SAW device is relatively mature. Compared with the traditional ultrasonic atomizer, it has a higher excitation frequency and consequently produces smaller aerosol droplets. The linear mean diameter in a SAW atomizer was found to be $19 \mu \mathrm{m}$ under an excitation frequency of $10 \mathrm{MHz}[3,4]$. Wang and $\mathrm{Hu}$ measured the atomized droplet size distribution generated by a SAW device in the order of $20 \mathrm{MHz}$. Analysis by a laser diffraction system revealed that the diameter distribution of droplets centered on three main areas, namely, $1 \mu \mathrm{m}, 10 \mu \mathrm{m}$, and $100 \mu \mathrm{m}$ [5]. Ju and Yamagata investigated a high-frequency SAW atomizer with resonance frequencies ranging from 50 to $95 \mathrm{MHz}$ and found that the mean diameters of atomized droplets were $5.7 \mu \mathrm{m}(50 \mathrm{MHz}), 4.4 \mu \mathrm{m}(75 \mathrm{MHz})$, and $2.7 \mu \mathrm{m}(95 \mathrm{MHz})$ [6]. Unlike an ultrasonic atomizer, where the energy is transferred in the form of a large block, the energy transfer of the SAW was localized on the substrate. The power required was therefore much less than what was required for ultrasonic atomization. It is possible to achieve atomization at 2-3 W of power, which allows the device to be hand-held; therefore, this was considered as an ideal device for applications such as pulmonary drug delivery, olfactory displays, and micro or nanoparticle synthesis [1-11].

However, SAW devices based on $\mathrm{LiNbO}_{3}$ without heat dissipation, even just a few watts, often break down. Fu et al. (2012) studied the ZnO SAW atomization device with an operating frequency of 23.1 $\mathrm{MHz}$ at an input radio frequency (RF) power of $21.2 \mathrm{~W}$ and an operating frequency of $37.2 \mathrm{MHz}$ and found that a much higher power $(>20 \mathrm{~W})$ was required for atomization [12]. Guo et al. (2015) investigated the ZnO SAW atomization device, which was excited with frequencies ranging from 37.2 $\mathrm{MHz}$ to $63.3 \mathrm{MHz}$, and also found that a much higher power (>20 W) was required for atomization [13]. With such a large input power, it was difficult to miniaturize the RF source to be hand-held. More importantly, the aerosol droplets generated during the atomization condensed in the air and dripped on the inter-digitated transducer (IDT), causing the electrodes to short-circuit [14-23]. This is one reason prevented the commercial application of SAW atomization.

To overcome the electrode-waterproofing problem, this paper proposes an SU-8-2002 film coating on the IDT and investigates the effect of the coating on atomization. SU-8-2002 is a high contrast, epoxy-based photoresistor designed for micromachining and other microelectronic applications. SU-8 2002 is an improved formulation of SU-8, which has been widely used by Micro-electromechanical Systems (MEMS) producers for many years. Film thicknesses of 2-200 microns can be achieved with a single coat process. Moreover, to the best of the authors' knowledge, there have been no studies thus far regarding the link between $\mathrm{LiNbO}_{3}$-based SAW atomization and its heating effects. In order to address the cracking problem of the $\mathrm{LiNbO}_{3}$ substrate caused by heat, we used an aluminum heat sink $(28 \mathrm{~mm} \times 19 \mathrm{~mm} \times 6 \mathrm{~mm})$ fitted beneath the substrate to enhance heat dissipation. Therefore, the 
characteristics of SAW atomization behavior based on the SU-8-2002 film, alongside waterproofing-test behavior and the thermal effects, were studied.

\section{Experiment Approach}

\subsection{SAW Device Design}

A SAW device was realized on a $128^{\circ} \mathrm{Y}-\mathrm{X} \mathrm{LiNbO}_{3}$ substrate. A $150 \mathrm{~nm}$-thick aluminum electrode consisting of 30 pairs of fingers was fabricated on a substrate using the standard lift-off technique and photolithography techniques. After using acetone, methanol, and deionized water to clean the wafer, the substrate was patterned with a positive photoresistor (AR-P 5350) using a photolithography technique used for making IDT electrode patterns. The substrate was then cleaned with a mild oxygen plasma (Technics). Subsequently, $150 \mathrm{~nm}$ of aluminum was sputtered using a RF-magnetron system on the patterned substrate. Finally, the photoresistor stripping was used to achieve the electrode. This design had a wavelength of $130 \mu \mathrm{m}$, an aperture of $10 \mathrm{~mm}$, and a center frequency of $30 \mathrm{MHz}$. To avoid short-circuiting, the thickness of SU-8-2002 needed to be thicker than the IDTs. Limited by the spin speed of the spin-coating machine (LAURELL, WS-650MZ-23NPPB) and the material viscosity of SU-8-2002, the spin speeds were set to $5000 \mathrm{r} / \mathrm{min}, 3500 \mathrm{r} / \mathrm{min}$, and $2500 \mathrm{r} / \mathrm{min}$, with a normalized thicknesses of SU-8-2002 of $3.2 \mu \mathrm{m}, 4.8 \mu \mathrm{m}$, and $5.2 \mu \mathrm{m}$, respectively. $\mathrm{LiNbO}_{3}$ wafers were then put on a $65{ }^{\circ} \mathrm{C}$ hotplate with good thermal control and uniformity to soft-bake for $5 \mathrm{~min}$, followed by the wafers being put on a $95^{\circ} \mathrm{C}$ hotplate to bake for $15 \mathrm{~min}$, after which the wafers were removed from the hotplate and allowed to cool to room temperature. Figure 1 shows the results of the film-coating test using the Probe profilometer (VEECO, Dektak 150). However, increasing the spin speed to a maximum of $8000 \mathrm{r} / \mathrm{min}$ did not decrease the film thickness further. Figure 2 shows three typical SEM images of the electrode surface with the film coating. Figure 2a shows an image of the electrode surface coated with SU-8-2002 at 30× magnification, suggesting the surface was well-coated with the film. Figure $2 \mathrm{~b}$ shows the electrode surface at $1000 \times$ magnification, suggesting that a small number of nanoparticles accumulated on the surface.

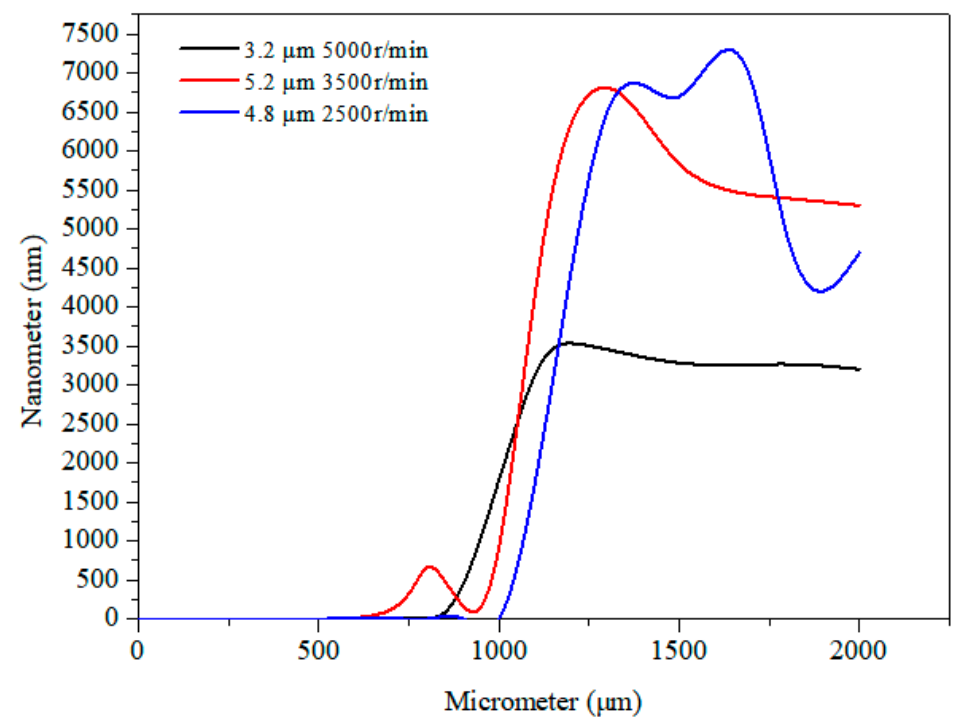

Figure 1. Thicknesses of the film coatings at different spin speeds. 

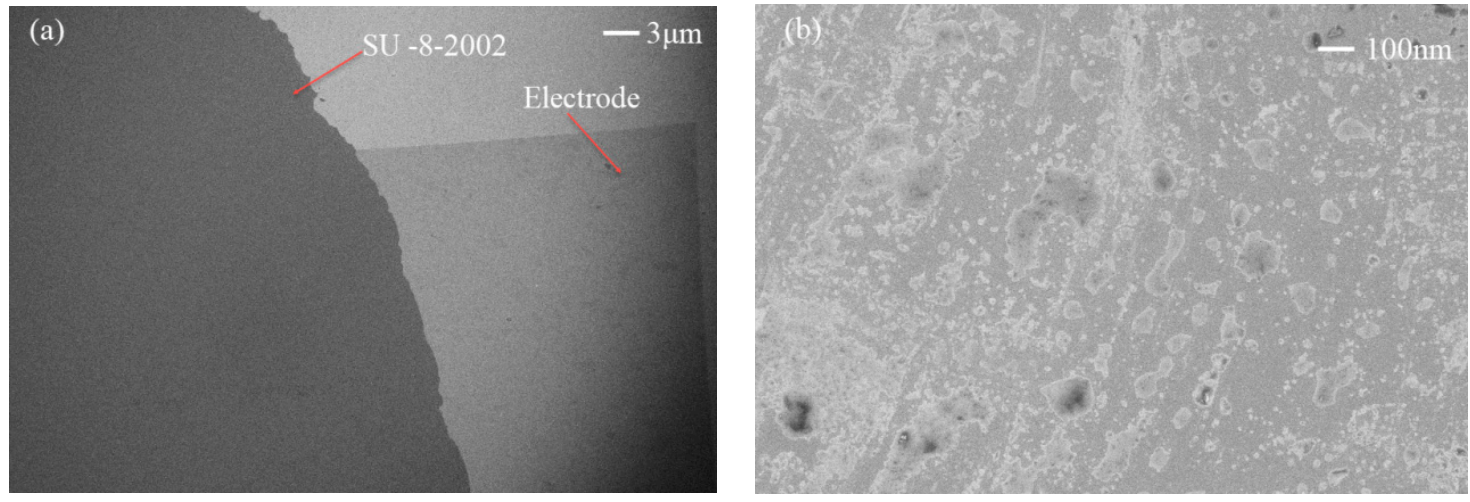

Figure 2. SEM images of the SU-8-2002 film coating. (a) The electrode surface at $30 \times$ magnification, (b) The electrode surface at $1000 \times$ magnification.

\subsection{Experimental Setup}

In order to evaluate the dispensing performance of the film coating, an observation system and a measurement system were employed, as shown in Figure 3. RF signals from a standard annunciator (RIGOL DSG3000) were amplified by a power amplifier (Mini-circuit LZY-22) and fed to the IDT. A RF power meter was used to measure the amplified RF signal power before connecting the IDT, and a polyester-cellulose paper (C1, Lymtech Scientific, USA) was used to draw liquid from a reservoir for continuous atomization. A high-speed camera (Optronis CP70-1HS-M-1900) with a frame rate of up to 10,000 frames per second was connected to a fixed-focus lens with a magnification of $0.7-4.5$ times (Photron D00545) and used to clearly observe the whole atomization phenomenon. A laser diffraction analyzer (OMCC, DP-02) was used to accurately measure the size distribution of the atomized droplets, and the real-time temperature changes of the droplets on the paper were measured using an infrared thermal imager (Gobi-640-GigE) and a thermocouple thermometer (UT325). The resonance frequencies of the SAW device were measured using a network analyzer (E5073C, Agilent).

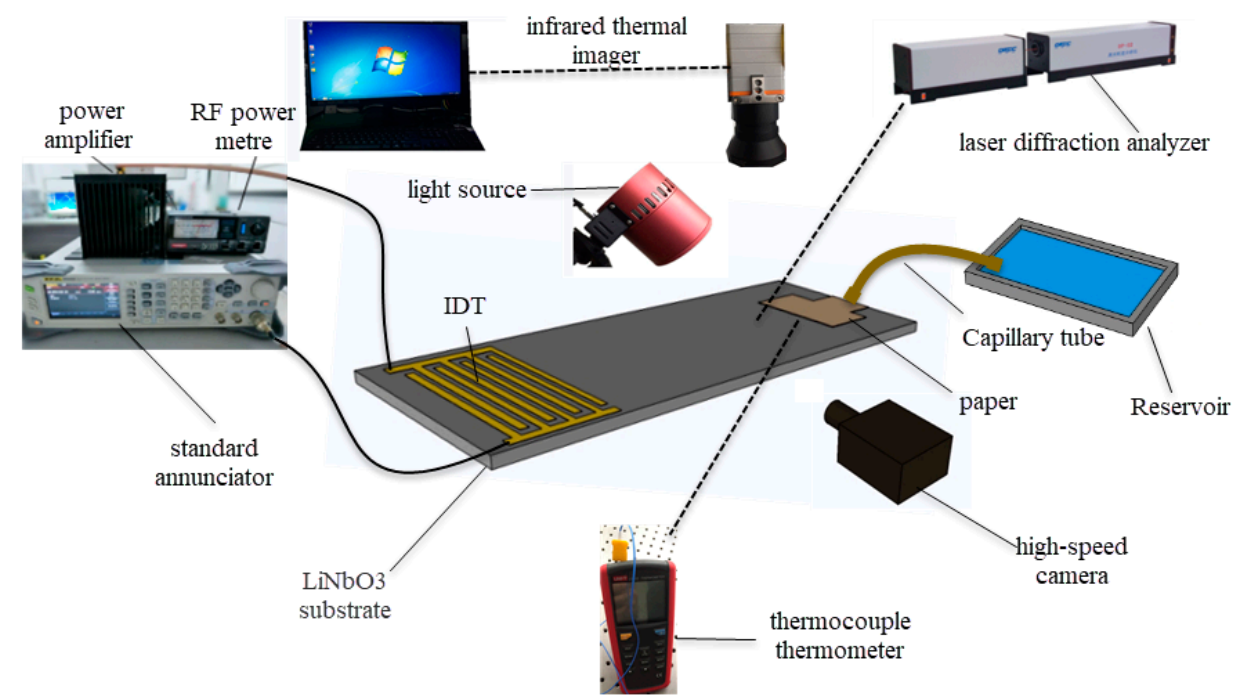

Figure 3. Experiment platform.

\section{Results and Discussion}

\subsection{Waterproof Test and the Influence of the Film Coating on Energy Radiation from the SAW}

In this section, the waterproof performance tests of the SAW devices with the film coating were investigated. Figure $4 \mathrm{a}-\mathrm{c}$ shows the dripping test on the electrode where the film-coating thickness 
was $3.2 \mu \mathrm{m}$. A syringe dripped the droplet vertically onto the IDT electrode, while the IDT electrode communicated with the signal. This process lasted $10 \mathrm{~min}$, and the drip rate was $5 \mathrm{~mL} / \mathrm{min}$. In this process, the liquid vibrated on the electrode and then constantly moved smoothly across the surface. If the electrode was not protected, the droplet would immediately cause the electrodes to short-circuit and crack. When the experiment was repeated at different dripping angles, the surface of the electrode was shown to be robust. Figure $4 \mathrm{~d}-\mathrm{f}$ shows how the water was sprayed onto the electrode, covering the surface of the chip with a large amount of liquid. After applying the SAW power, a large amount of liquid vibrated on the surface. During the low power experiment, the SAW energy dissipated in a large amount of liquid and did not appear to move the liquid. This process lasted $1 \mathrm{hand}$ the film coating was not damaged. Similar phenomena appeared in other coating experiments with different film thicknesses.
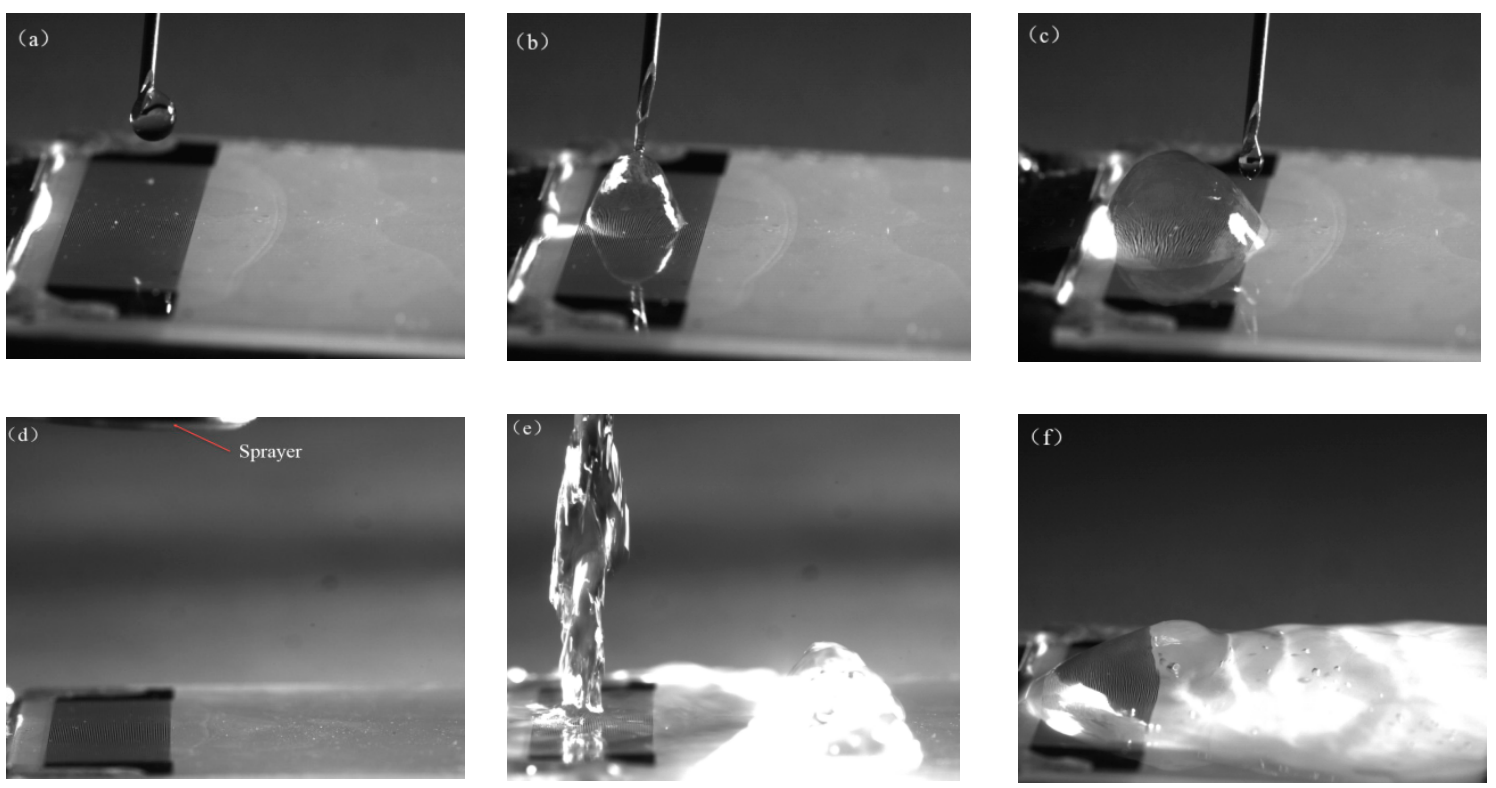

Figure 4. Waterproof performance tests of the surface acoustic wave (SAW) device with the film coating. $(\mathbf{a}-\mathbf{c})$ The electrode dripping test. $(\mathbf{d}-\mathbf{f})$ Corresponding images of the electrode water-spraying test.

Figure 5 shows the frequency domain characteristic results under different conditions. Before film coating, the center frequency of the fabricated device was $29.80 \mathrm{MHz}$ due to a manufacturing process error and the reflection spectrum (S11) was $-15 \mathrm{~dB}$. The film coating of SU-8-2002 changed the impedance of the device; therefore, the center frequency changed from $29.80 \mathrm{MHz}$ to $29.55 \mathrm{MHz}$, as illustrated in Figure 5, which represents a film coating of $3.2 \mu \mathrm{m}$. It was observed that in the frequency domain characteristic results of the short-circuiting of the electrode, which was caused by dripping the droplet onto the unprotected electrode, there were no visible resonant frequencies. Compared with this, after film coating and liquid testing, the electrode worked normally. It should be pointed out that the resonant frequencies were kept constant after liquid testing, which was consistent with the pre-testing, and that the reflection spectrum of film coating decreased by around $10 \mathrm{~dB}$. Thus, the electrode protection appeared to be successful. The waterproof performance was tested several times on the other SAW devices with different coating thicknesses, indicating that the film coating on the electrode was robust. 


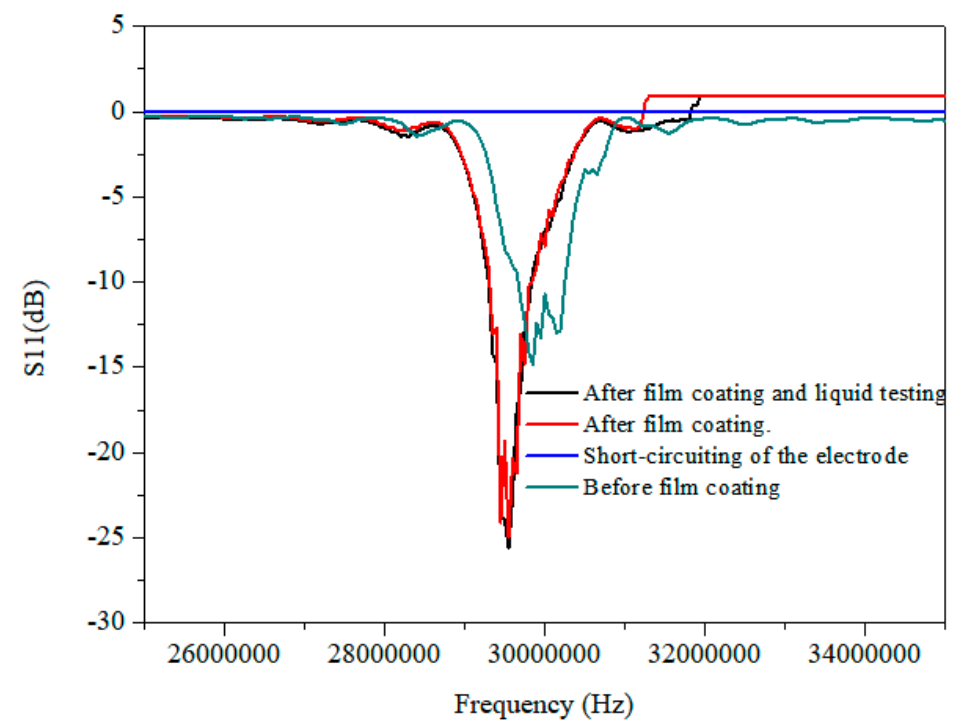

Figure 5. The frequency domain characteristic results under different conditions.

A $10 \mu \mathrm{L}$ water droplet was deposited directly onto the IDT via micro-syringe. Figure 6a-c shows the movement of the droplet on the SAW device surface before and after interaction with a SAW at a center frequency of $30 \mathrm{MHz}$ and an RF power of $4.68 \mathrm{~W}(-7.5 \mathrm{dBm})$ for different coating thicknesses. Before applying the RF signal, the droplet was at rest on the IDT. After applying the SAW power, the IDT generated a pressure gradient that caused the droplet to deform into a conical shape; as the energy in the droplet increased, the droplet began to creep. As shown in Figure 6a, with a coating thicknesses of $3.2 \mu \mathrm{m}$, the undulation of the droplet surface led to the elongation of a crest at $10 \mathrm{ms,}$ then crept to the end of the device, where it began to eject droplets at $102 \mathrm{~ms}$. With increasing coating thicknesses, the time that the droplet took to creep to the end of the device and deform into a conical shape increased, as shown in Figure $6 \mathrm{~b}$. With a coating thickness of $5.2 \mu \mathrm{m}$, the droplet was observed to vibrate, but without forming a crest at $35 \mathrm{~ms}$ followed by a very slow creep on the surface of the device; no deformation or ejection occurred at $3200 \mathrm{~ms}$. This was because as the thickness of the coating increased, the film absorbed the energy of the SAW. The following sections discuss the effect of the coating on atomization characteristics and heat dissipation.
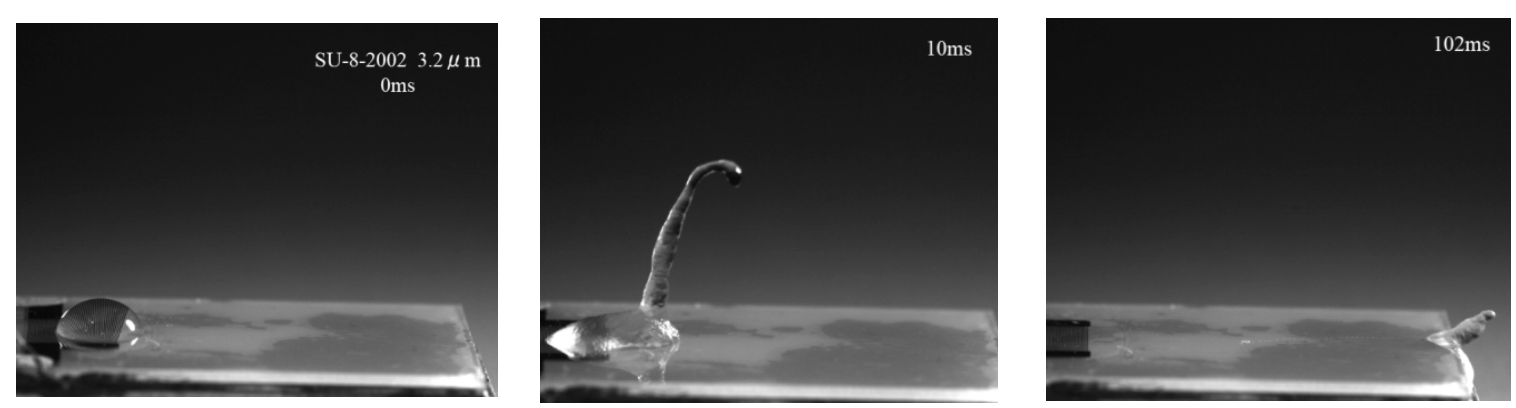

(a)

Figure 6. Cont. 

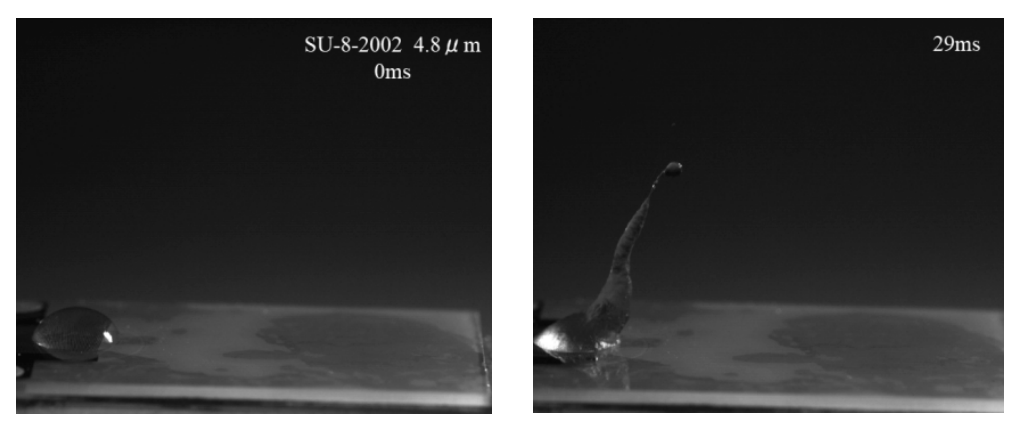

(b)
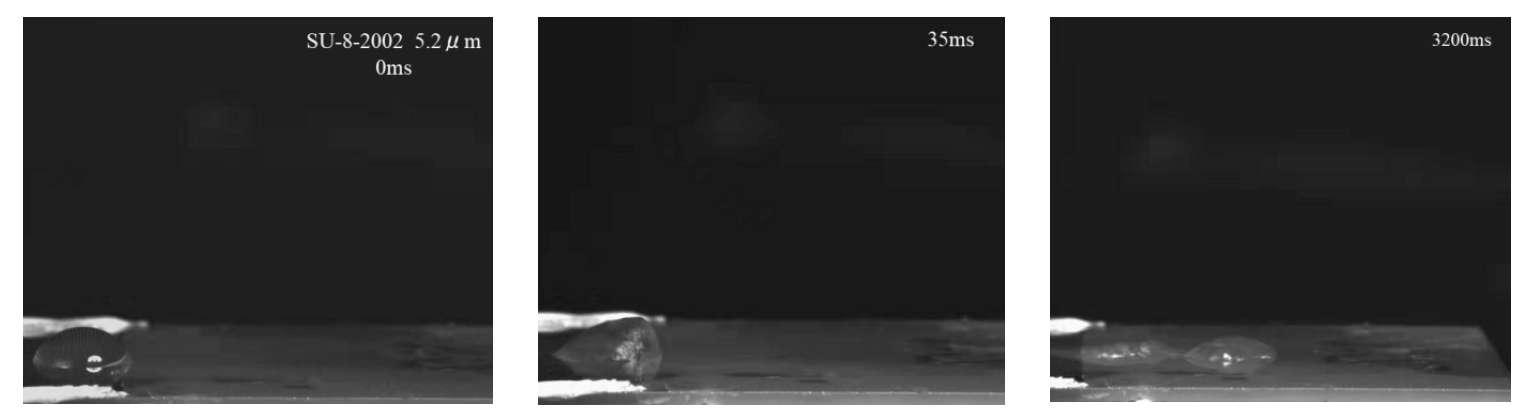

(c)

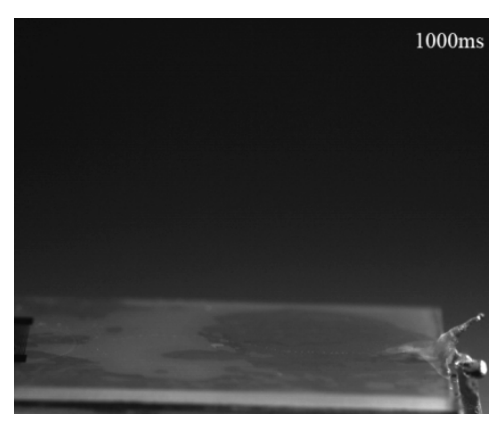

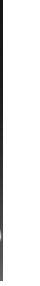



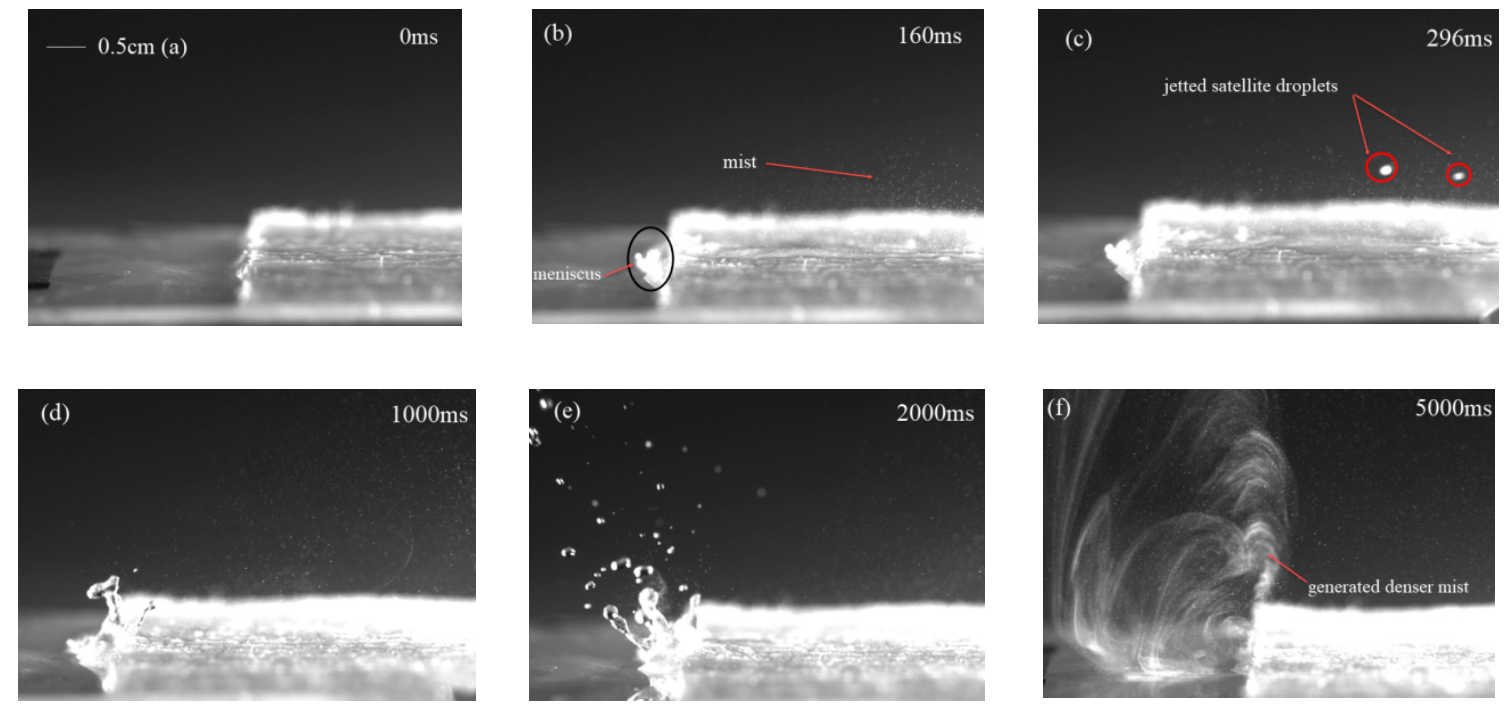

Figure 7. Atomization behavior of $3.2 \mu \mathrm{m} \mathrm{SU-8-2002} \mathrm{interdigitated} \mathrm{transducer} \mathrm{(IDT)} \mathrm{coating} \mathrm{thicknesses}$ with a SAW frequency of $30 \mathrm{MHz}$ at a power of $4.86 \mathrm{~W}$. (a) $0 \mathrm{~ms}$, (b) $160 \mathrm{~ms}$, (c) $296 \mathrm{~ms}$, (d) $1000 \mathrm{~ms}$, (e) $2000 \mathrm{~ms}$, and (f) $5000 \mathrm{~ms}$.
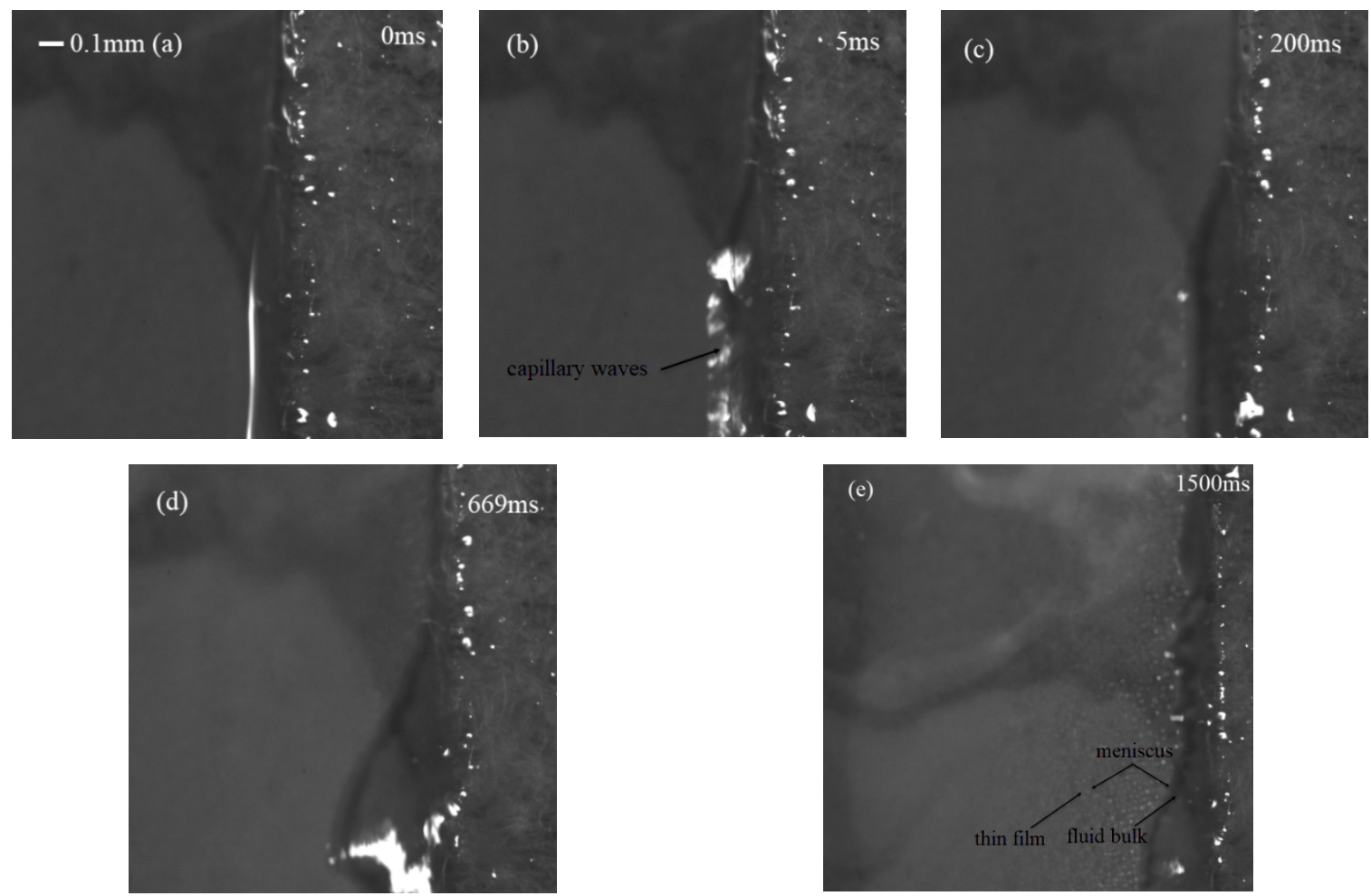

Figure 8. A high-magnification image of the movement of the liquid on the paper. (a) $0 \mathrm{~ms}$, (b) $5 \mathrm{~ms}$, (c) $200 \mathrm{~ms}$, (d) $669 \mathrm{~ms}$, (e) $1500 \mathrm{~ms}$.

Aerosol size distribution is an important characteristic of atomization. The mean diameter can be expressed based on the balance between the viscous and capillary force [21]:

$$
D \sim \lambda \sim \gamma H^{2} / \mu f L^{2}
$$

where $D$ is the mean diameter, $\lambda$ is the wavelength of the capillary wave, $\gamma$ is the surface tension, $\mu$ is the viscosity, $H$ and $L$ represent the height and length of the parent drop or film, and $f$ is the capillary 
frequency. In the experiment, the liquid had a viscosity $\mu$ of $10^{-3} \mathrm{~kg} / \mathrm{ms}$ and a surface tension $\gamma$ of $10^{-2}$ $\mathrm{N} / \mathrm{m}$. The bulk region had a capillary frequency $f_{c}$ of $104 \mathrm{~Hz}$ and $\mathrm{H} / \mathrm{L}$ close to 0.1 [9]. When these values are substituted into Equation (1), the prediction of $D$ is around $10 \mu \mathrm{m}$. When the thickness of this region increases, i.e., $H / L$ increases from about 0.5 to 1 , then the prediction of $D$ is above $100 \mu \mathrm{m}$. In the thin film, $L$ is equal to $2 \lambda_{\mathrm{SAW}}, H \approx 7 / 8 \lambda_{l}{ }^{*} \cos \theta_{R}$, where $\lambda_{l}$ represents the sound wavelength, $\theta_{R} \approx 22^{\circ}$, and the capillary frequency $f_{c}$ is $10^{6} \mathrm{~Hz}$. When these values are substituted into Equation (1), the prediction of $D$ is around $1 \mu \mathrm{m}$. The particle size distribution was measured with a laser diffraction analyzer. Figure 9 shows the volume-based droplet size distribution. In all cases, the particle size distribution showed trimodal distribution, which was consistent with previous studies (Qi et al., 2008, 2010; Wang and Hu, 2016). The film coating on SU-8-2002 had little effect on the particle size distribution. There were three peaks in this case: The first peak was around 1-2 $\mu \mathrm{m}$, the second peak was around 10-30 $\mu \mathrm{m}$, and the third peak was above $100 \mu \mathrm{m}$. The largest droplets with diameters above $100 \mu \mathrm{m}$ were generated by jetting the satellite droplets, which were ejected from the bulk region due to the direct interaction of SAW with the liquid, while the second peak of droplets was governed by Eckart streaming, with the droplets coming from the meniscus. At this stage, the Eckart streaming caused the capillary waves on the meniscus liquid surface; as the energy increased the capillary waves became unstable. The third range of droplets was due to Schlichting streaming, where the diameter of a droplet was determined by the inertia-capillary resonance, thereby producing a smaller mist than the previous stage.

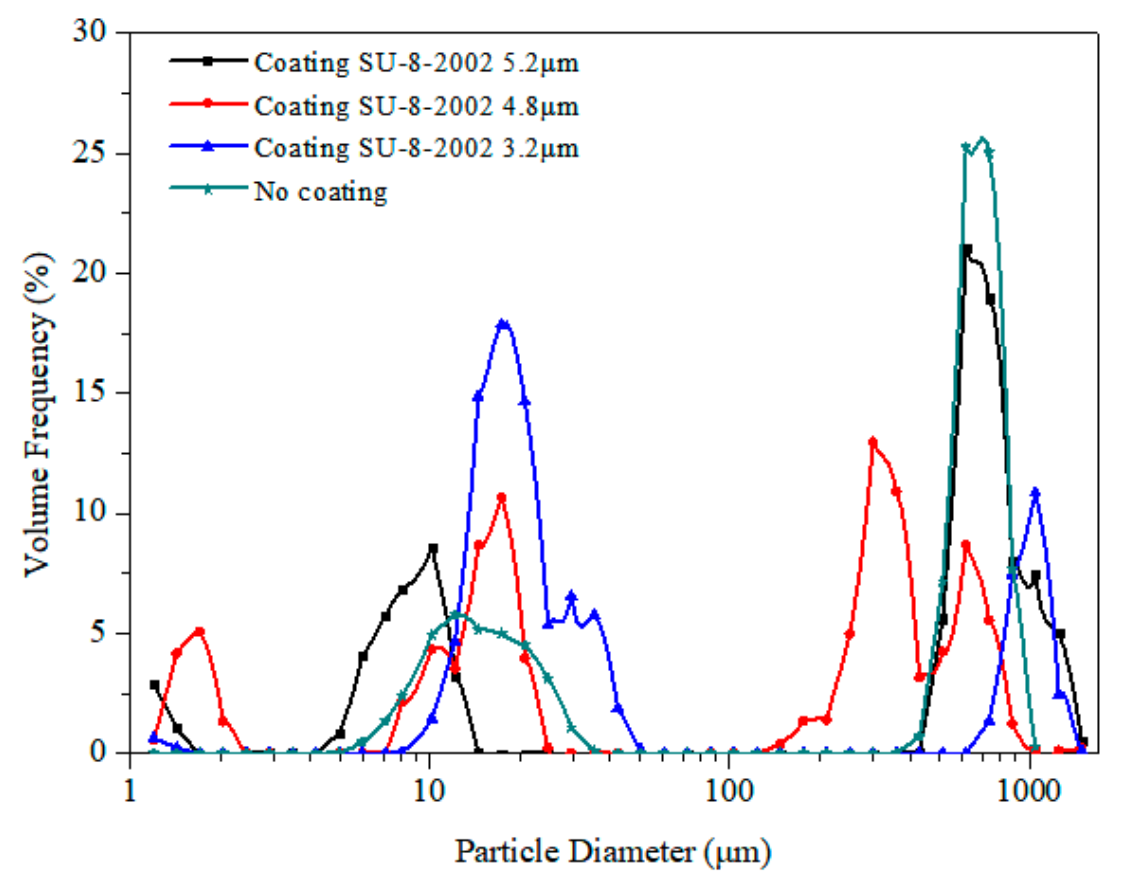

Figure 9. The volume-based droplet size distribution of atomization at $4.68 \mathrm{~W}$ with a $30 \mathrm{MHz}$ excitation radio frequency (RF signal), measured with a laser diffraction analyzer.

The atomization speed as a function of the SAW power is shown as Figure 10. In general, with the increase in power, the atomization speed increases significantly. In the case of no film coating, the atomization rate at $5.26 \mathrm{~W}$ was $0.5 \mu \mathrm{L} / \mathrm{s}$, while with a film coating of $3.2 \mu \mathrm{m}$ at the same power, the atomization rate was $0.45 \mu \mathrm{L} / \mathrm{s}$. However, with a film coating of $5.2 \mu \mathrm{m}$, the atomization rate decreased dramatically to $0.23 \mu \mathrm{L} / \mathrm{s}$. 


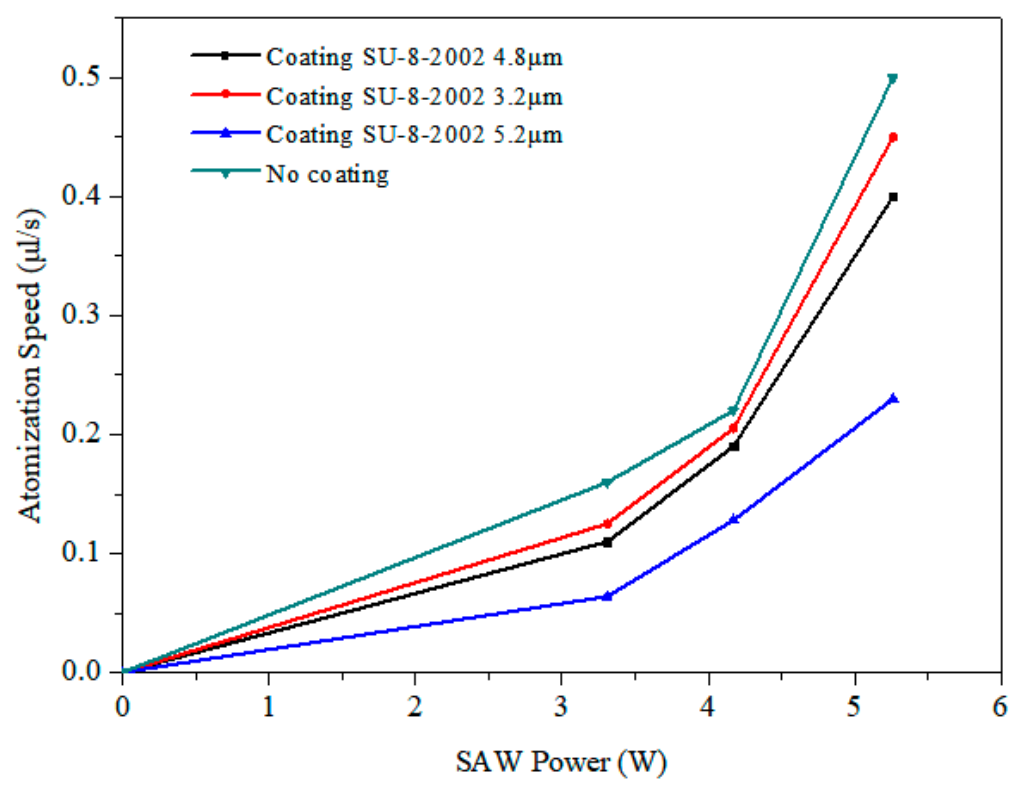

Figure 10. Atomization speed (i.e., droplet volume divided by the total atomization) over the SAW power.

\subsection{Heating Effects}

Heat was generated from the activity of the SAW device. This caused a breakdown or cracks in the $\mathrm{LiNbO}_{3} \mathrm{SAW}$ device due to the brittleness of the ceramic material under a large thermal shock, a problem which has continuously plagued researchers.

Researchers found that the main thermal effect caused by temperature changes on a $\mathrm{LiNbO}_{3}$ surface without any heat sink was so great that it cracked easily. We therefore placed a $28 \mathrm{~mm} \times 19$ $\mathrm{mm} \times 6 \mathrm{~mm}$ aluminum heat sink behind the $\mathrm{LiNbO}_{3}$ substrate to improve the heat distribution. The SAW device was excited with a power of $4.68 \mathrm{~W}$ and a central frequency of $30 \mathrm{MHz}$, and an infrared thermal image was used to study the thermal effect distribution of the device under different coating thicknesses. It can be seen from Figure 11 that all of the devices reached uniform temperatures within $5 \mathrm{~s}$, although, at the beginning, the temperature of the film coating part was higher than the other parts of the surface. In order to study the temperature changes of the liquid based on the strip atomization, a thermocouple thermometer was used to measure the temperature of the atomized liquid at the front edge of the paper. The temperature of the atomized liquid under different coating thicknesses is shown in Figure 12. It was observed that the temperature initially increased rapidly and gradually reached a steady state. With no film coating, the temperature increased to $82^{\circ} \mathrm{C}$. As the thickness of the film coating increased, the temperature decreased a little in comparison to no coating; the temperature of the $3.2 \mu \mathrm{m}$ film coating increased to $78^{\circ} \mathrm{C}$ within $2 \mathrm{~min}$. Under these conditions, the heating effect did not contribute much to the atomization process. Thus, using a heat sink was shown to allow the lithium niobate substrate to reach a uniform temperature immediately while preventing the surface from cracking. Moreover, the film coating of SU-8-2002 had little effect on the temperature uniformity. 

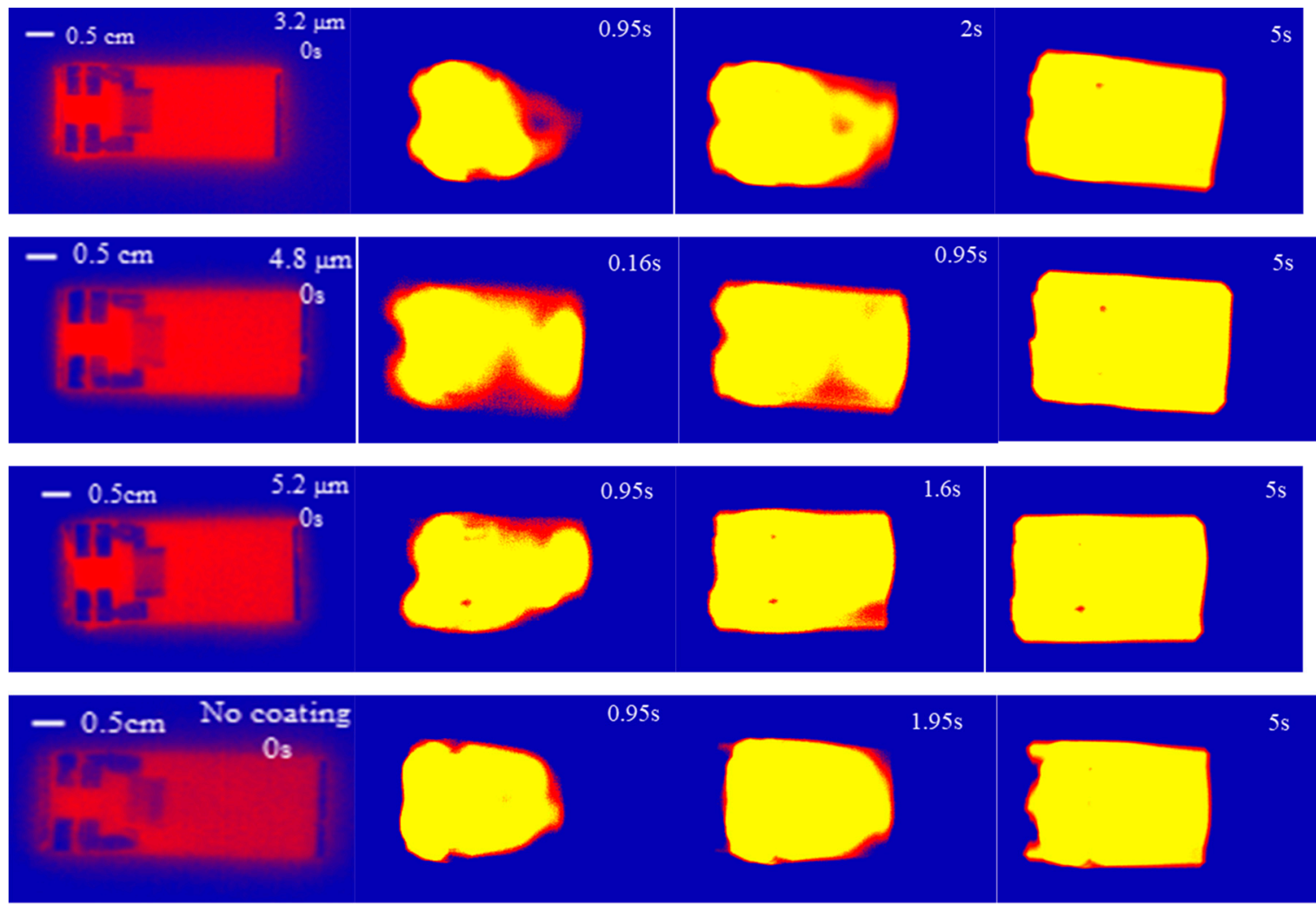

Figure 11. The thermal effect distribution of the device under different coating thicknesses.

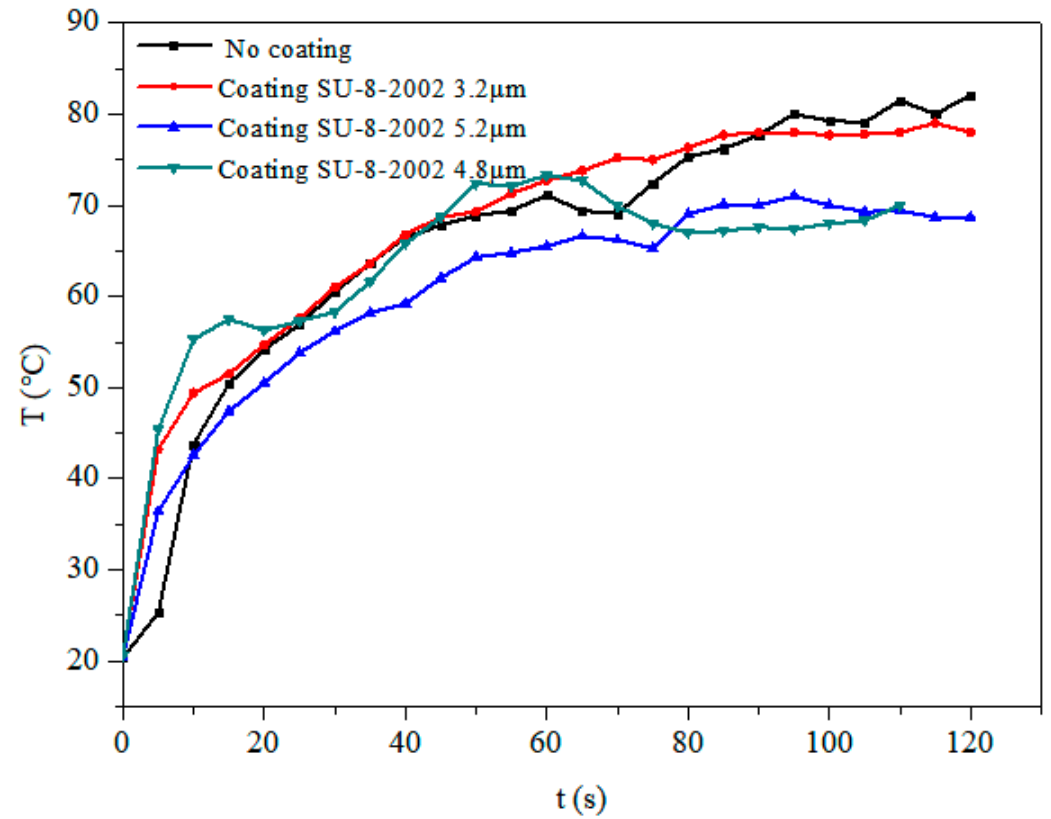

Figure 12. Temperature changes of the atomized liquid under different coating thicknesses.

\section{Conclusions}

In summary, the problem of aerosol droplets generated during atomization condensing in the air and dripping on to the IDT, thereby causing the electrodes to short-circuit, was solved using coating with a SU-8-2002 film. This study investigated the effect of the SU-8-2002 film on atomization behavior and heating through an experimental approach. During the atomization process, a meniscus film formed at the front of the strip and a capillary wave formed on the meniscus liquid surface, thereby 
destabilizing the free surface of liquid and, consequently, the jetting of satellite droplets. The particle size distribution showed trimodal distribution, which the film coating of SU-8-2002 had little effect on. When the film coating had a thickness of $3.2 \mu \mathrm{m}$, the atomization rate was $0.45 \mu \mathrm{L} / \mathrm{s}$, whereas, when there was no film coating, the atomization rate was $0.5 \mu \mathrm{L} / \mathrm{s}$ at a power of $5.26 \mathrm{~W}$. Investigation of the thermal effect revealed that it did not contribute much to the atomization process in the aforementioned set ups. In addition, SAW devices with SU-8-2002 film coatings have the potential for commercial applications and for integration with other microfluidic systems.

Author Contributions: Q.-Y.H. conceived the research. H.H. supervised the research. Q.-Y.H. designed the experiments. Q.-Y.H. and J.-L.H. performed the experiments. Q.-Y.H., J.-L.H., Y.-L.L., X.-Q.Y., H.H. contributed to the manuscript preparation. All authors have given approval to the final version of the manuscript.

Funding: This work was supported by the Shenzhen Government Research Foundation JCY20170413105740689 and JSGG20170412143346791, and Dongguan city graduate cultivation and development center.

Conflicts of Interest: The authors declare no conflict of interest.

\section{References}

1. Wood, R.W.; Loomis, A.L. The physical and biological effects of high-frequency sound-waves of great intensity. J. Frankl. Inst. 1928, 205, 151-153. [CrossRef]

2. Lang, R.J. Ultrasonic atomization of liquids. J. Acoust. Soc. Am. 1962, 34, 6-8. [CrossRef]

3. Kurosawa, M.; Watanabe, T.; Futami, A.; Higuchi, T. Surface acoustic wave atomizer. Sens. Actuators A Phys. Sens. 1995, 50, 69-74. [CrossRef]

4. Kurosawa, M.; Watanabe, T.; Higuchi, T. Surface Acoustic Wave Atomizer with Pumping Effect. In Proceedings of the IEEE Micro Electro Mechanical Systems, Amsterdam, The Netherlands, 29 January-2 February 1995; pp. $25-30$.

5. Wang, J.X.; Hu, H.; Ye, A.; Chen, J.; Zhang, P. Experimental investigation of surface acoustic wave atomization. Sens. Actuators A Phys. 2016, 238, 1-7. [CrossRef]

6. Ju, J.; Yamagata, Y.; Ohmori, H.; Higuchi, T. Standing wave type surface acoustic wave atomizer. Sens. Actuators A Phys. 2008, 147, 570-575. [CrossRef]

7. Qi, A.; Friend, J.R.; Yeo, L.Y.; Morton, D.A.; McIntosh, M.P.; Spiccia, L. Miniature inhalation therapy platform using surface acoustic wave microfluidic atomization. Lab A Chip 2009, 9, 2184-2193. [CrossRef]

8. Qi, A.; Friend, J.R.; Ho, J. The extraction of liquid, protein molecules and yeast cells from paper through surface acoustic wave atomization. Lab A Chip 2010, 10, 470-476. [CrossRef]

9. Qi, A.; Friend, J.R.; Yeo, L.Y. Investigation of SAW Atomization. In Proceedings of the IEEE International Ultrasonics Symposium, Rome, Italy, 20-23 September 2009; pp. 787-790.

10. Qi, A.; Friend, J.R.; Yeo, L.Y.; Friend, J.R. Interfacial destabilization and atomization driven by surface acoustic waves. Phys. Fluids 2008, 20, 074103. [CrossRef]

11. Fu, Y.Q.; Li, Y.; Zhao, C.; Placido, F.; Walton, A.J. Surface acoustic wave nebulization on nanocrystalline ZnO film. Appl. Phys. Lett. 2012, 101, 194101. [CrossRef]

12. Guo, Y.J.; Dennison, A.P.; Li, Y.; Luo, J.; Zu, X.T.; Mackay, C.L.; Langridge-Smith, P.; Walton, A.J.; Fu, Y.Q. Nebulization of water/glycerol droplets generated by $\mathrm{ZnO} / \mathrm{Si}$ surface acoustic wave devices. Microfluid. Nanofluidics 2015, 19, 273-282. [CrossRef]

13. Anand, S.; Nylk, J.; Neale, S.L.; Dodds, C.; Grant, S.; Ismail, M.H.; Reboud, J.; Cooper, J.M.; McGloin, D. Aerosol droplet optical trap loading using surface acoustic wave nebulization. Optics Express 2013, 21, 30148-30155. [CrossRef] [PubMed]

14. Ju, J.; Yamagata, Y.; Ohmori, H.; Higuchi, T. High-frequency surface acoustic wave atomizer. Sens. Actuators A Phys. 2008, 145, 437-441. [CrossRef]

15. Winkle, A.; Harazim, S.M.; Menzel, S.B.; Schmidt, H. SAW-based fluid atomization using mass-producible chip devices. Lap A Chip 2015, 15, 3793-3799. [CrossRef]

16. Rajapaksa, A.; Qi, A.; Yeo, L.Y.; Coppel, R.; Friend, J.R. Enabling practical surface acoustic wave nebulizer drug delivery via amplitude modulation. Lap A Chip 2014, 14, 1858-1865. [CrossRef] [PubMed]

17. Chen, J.; Hu, H.; Chen, Y. Experimental investigation of microchannel ejection based on a novel microfluidic coating nozzle. Surf. Coat. Technol. 2019, 38, 721-725. [CrossRef] 
18. Yeo, L.Y.; Friend, J.R.; McIntosh, M.P.; Meeusen, E.N.; Morton, D.A. Ultrasonic nebulization platforms for pulmonary drug delivery. Expert Opin. Drug Deliv. 2010, 7, 663-679. [CrossRef] [PubMed]

19. Friend, J.R.; Yeo, L.Y.; Arifin, D.R.; Mechler, A. Evaporative self-assembly assisted synthesis of polymeric nanoparticles by surface acoustic wave atomization. Nanotechnology 2008, 19, 145301. [CrossRef]

20. Tan, M.K.; Friend, J.R.; Yeo, L.Y. Direct visualization of surface acoustic waves along substrates using smoke particles. Appl. Phys. Lett. 2007, 91, 224101. [CrossRef]

21. Kurosawa, M.; Futami, A.; Higuchi, T. Characteristics of liquid atomization using surface acoustic wave. Transducers 1997, 97, 801-804.

22. Collins, D.J.; Manor, O.; Winkler, A.; Schmidt, H.; Friend, J.R.; Yeo, L.Y. Atomization off thin water films generated by high-frequency substrate wave vibrations. Phys. Rev. E 2012, 86, 056312. [CrossRef]

23. Huang, H.Y.; Chiang, H.J.; Wu, C.Z.; Lin, Y.; Shen, Y.K. Analysis on Characteristics of ZnO Surface Acoustic Wave with and without Micro-Structures. Micromachines 2019, 10, 434. [CrossRef] [PubMed]

(C) 2019 by the authors. Licensee MDPI, Basel, Switzerland. This article is an open access article distributed under the terms and conditions of the Creative Commons Attribution (CC BY) license (http://creativecommons.org/licenses/by/4.0/). 